\title{
Cibercultura E EduCAÇÃo: PONTOS E CONTRAPONTOS entre a Visão de Pierre Lévy e David Lyon
}

\author{
Angela Luzia Miranda ${ }^{1}$
}

\begin{abstract}
Resumo: $\mathrm{O}$ artigo visa a confrontar o visível otimismo de Pierre Lévy sobre a cibercultura como espaço de produção da inteligência coletiva e da educaçâo para a democratização social, com a postura crítica de David Lyon acerca da cultura da vigilância e seus efeitos sociopolíticos, na era da cibercultura. De cunho filosófico e qualitativo, cuja fonte de pesquisa é essencialmente bibliográfica, trata-se de um estudo comparativo que busca estabelecer as diferenças elementares entre a postura de Lévy e Lyon sobre a cibercultura. Em consequência, e reconhecendo as teses de Lyon sobre a ilusão do anonimato e os riscos do fim da privacidade, na era da cibercultura, o estudo termina por apontar alguns indicativos sobre as novas práticas educativas nesse contexto.
\end{abstract}

Palavras-chave: Cibercultura. Educação. Ciberdemocracia. Vigilância.

Nossos avatares semânticos querem nos dar a oportunidade de refletir sobre nossa experiência de vida, proteger nossa saúde, planejar melhor nossos empreendimentos cognitivos, gerenciar nossas relaçóes sociais.

(LÉVY, 2016, p. 140).

A vigilância suaviza-se especialmente no reino do consumo. Velhas amarras se afrouxam à medida que fragmentos de dados pessoais obtidos para um objetivo são facilmente usados com outro fim.

(BAUMAN; LYON, 2013, p. 3).

${ }^{1}$ Doutora em Filosofia e Professora Associada da Universidade Federal do Rio Grande do Norte, Natal, RN - Brasil. Coordenadora do Grupo de Estudos Phrònesis: Estudos em Filosofia, Ciência, Tecnologia e Sociedade. (D) https://orcid.org/0000-0002-4516-7301 E-mail: angelalmiranda@gmail. com. Em seu projeto inicial, esse estudo contou também com a colaboração de Diego Silveira Souza, doutorando em Neurociências da Universidade Federal do Rio Grande do Norte.

https://doi.org/10.1590/0101-3173.2021.v44n1.04.p45

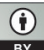

This is an open-access article distributed under the terms of the Creative Commons Attribution License. 


\section{INTRODUÇÃo}

Representa a cibercultura um espaço democrático e de produção do conhecimento para o exercício da cidadania? E, em consequência, que papel cumpre a educação, no contexto da cibercultura? Desde o surgimento das chamadas tecnologias da informação, tais questốes têm pautado a discussão sobre os novos rumos da sociedade e da educação. Sobre sua avaliação, de um lado, tem-se o argumento dos seus entusiastas e otimistas, como é o caso da teoria precursora sobre cibercultura e ciberdemocracia de Pierre Lévy. Por outro lado, outros estudiosos do assunto, como David Lyon, têm manifestado profunda preocupação com os rumos dessa nova dimensão da tecnologia e seus efeitos sociais, políticos e educativos para as sociedades informatizadas. O presente artigo, portanto, trata de abordar tal problemática, submetendo a posição otimista de Lévy (1999, 2000, 2003, 2010, 2014a, 2014b, 2016, 2017) a respeito da cibercultura como espaço de produçáo da inteligência coletiva ao crivo e análise crítica, particularmente representados pela leitura de Lyon $(1994,2006,2015)$ sobre a cultura da vigilância e a ilusão do anonimato e da privacidade na cibercultura, seguida de perto pela leitura de Bauman (BALMAN; LYON, 2013; RAMONET, 2016; ASSANGE, 2013, 2015; HARARI, 2016; MATTELART; 2006; RÜDIGER, 2011).

De caráter filosófico, bibliográfico, comparativo e analítico, este estudo busca primeiramente identificar, através de uma leitura revisitada e atualizada do pensamento de Lévy, os conceitos e relaçôes que o autor estabelece entre cibercultura, ciberespaço, ciberdemocracia, inteligência coletiva (e reflexiva) e a educação em direção a uma sociedade da informação e do conhecimento. Em seguida, procura-se promover o contraponto, com as teses apresentadas por Lyon sobre a cultura da vigilância e suas implicaçôes sociopolíticas, no contexto da cibercultura.

Contudo, mais que oferecer um estudo comparativo sobre tal problemática, o propósito deste trabalho é também o de indagar, em consequência, o que significa educar para o exercício da cidadania, na era da cibercultura. Desde um ponto de vista filosófico, em nosso entendimento, a práxis educativa nesse contexto deve ir muito além do mero "exercício de uma nova cidadania de software”, como postula Lévy (2016, p. 139), já que requer uma postura baseada na "contravigilância" para a garantia e proteção de direitos fundamentais, como reivindica Lyon (2015). 


\section{A CiBERCULTURA COMO ESPAÇO DEMOCRÁTICO DE PRODUÇÁO DO CONHECIMENTO}

Reconhecido pela sua postura otimista em relação à cibercultura e à ciberdemocracia, desde que se tornou mundialmente reconhecido pelo lançamento de suas obras Inteligência Coletiva, em 1994 (1999), e Cibercultura, em 1997 (2000), o filósofo e educador Pierre Lévy tem contribuído significativamente para o avanço das ciências da informação e para o incremento da educaçáo por meio da cibercultura. Para ele, é na esfera da virtualidade, onde hoje se produz o conhecimento, que também se gesta o espaço da cibercultura. Lévy (1999, p. 17) define a cibercultura como "o conjunto de técnicas (materiais e intelectuais), de práticas, de atitudes, de modos de pensamento e de valores que se desenvolvem juntamente com o crescimento do ciberespaço.” O ciberespaço requisita uma comunicação interativa e comunitária, a qual, por sua vez, possibilita a abertura para a criação de um tipo de inteligência que se torna coletiva. Daí o surgimento de um novo modo de cultura baseado na troca informacional e interativa do ciberespaço, a cibercultura.

Mas o ciberespaço não é somente a infraestrutura técnica que alberga as tecnologias da informação. Mais que isso, o ciberespaço "propóe uma liberdade de expressão e de navegação, na esfera informacional, infinitamente maior do que todas as outras mídias anteriores e, simultaneamente, uma ferramenta sem precedente de inteligência coletiva." (LÉVY, 2003, p. 32; LEMOS; LÉVY, 2010, p. 55). Segundo Lévy (2000, p. 28), é a inteligência coletiva

[...] uma inteligência distribuída por toda parte, incessantemente valorizada, coordenada em tempo real, que resulta de uma mobilizaçáo efetiva das competências, tendo como objetivo o reconhecimento e o enriquecimento mútuos das pessoas, e náo o culto de comunidades fetichizadas ou hipostasiadas.

Logo, a inteligência coletiva não está restrita a uns poucos privilegiados: ela pertence à humanidade. Seu ambiente é o do ciberespaço, que "[...] suporta tecnologias intelectuais que amplificam, exteriorizam e modificam numerosas funçōes cognitivas humanas.” (LÉVY, 1999, p. 157). Assim, na cibercultura, há espaços de conhecimentos abertos, contínuos, em fluxo, não lineares, adaptando-se de acordo com os objetivos e contextos. Nessa nova dinâmica de espaço de produção do conhecimento, observa Lévy (2003, p. 85), "as novas redes de comunicação transformaram a Terra numa única zona regional centrada na metrópole ciberespacial.” Portanto, é nesse contexto 
virtual de troca de informaçóes, armazenamento de dados, intercâmbio de saberes, que a democracia e o ciberespaço se geram mutuamente, formando, pois, a ciberdemocracia.

O ciberespaço se transforma, então, numa esfera das decisões públicas e coletivas dos cidadãos, onde o computador - e, com ele, todas as outras formas de tecnologias informacionais - é uma ferramenta necessária na mediação e constituição desse novo modelo societário (LÉVY, 2000, p. 67). Nele, os indivíduos agem e interagem coletivamente, numa espécie de democracia direta, na qual as decisóes podem ter a magnitude e a extensão, inclusive, do poder de Estado. Trata-se de uma nova identidade política dos cidadáos, que figurariam numa paisagem política em constante movimento, "[...] pelo apoio que daria a determinados problemas (que eles julgam prioritários), a determinadas posiçốes (as quais eles aderem) e a determinados argumentos (que eles retomam por conta própria).” (LÉVY, 2000, p. 65).

O caso da Primavera Árabe, em 2011, poderia ser um exemplo emblemático nesse sentido. Vale lembrar que, na tentativa de coibir o movimento iniciado através das redes sociais, o presidente Mubarak chegou a emitir a ordem de desligar a rede. Tarde demais, considerando seu efeito virtual e potencialmente universal, o qual transcendia a jurisdição e o espaço físico do Estado-nação. Nisso se confirmam os aspectos ressaltados por Lévy acerca da inteligência coletiva, numa ciberdemocracia planetária de livre expressão e possibilidades. De acordo com suas previsôes, ocorrerá um enfraquecimento dos limites territoriais dos Estados-nação e, consequentemente, uma unificaçáo das culturas numa cibercultura universal. A inteligência coletiva propiciará esse futuro, de trocas e comunhão da comunidade mundial: um autêntico espaço de ciberdemocracia. Essa posição de Lévy, digase de passagem, é também corroborada pelas Naçóes Unidas. Num relatório publicado em 2011 sobre o direito de acesso à internet (em plena efervescência da Primavera Árabe), a ONU sustentava: "[...] a Internet é um dos instrumentos mais poderosos do século 21 para o aumento transparência na condução dos poderosos, o acesso à informação, e para facilitar a participação ativa dos cidadãos na construção de sociedades democráticas." (NAÇÕES UNIDAS, 2011).

Por outro lado, o filósofo francês também tem consciência dos seus riscos, inclusive, o risco da ciberdemocracia se tornar uma "ciberditadura". Contudo, em resposta a essa questão, Lévy (2014a) sustenta que, apesar dos riscos inerentes, não devemos temer o uso da rede e, sim, controlar seus riscos. Ou seja, o controle desses riscos deve permanecer em poder do próprio usuário. Ocorre que, por vezes, observa o próprio Lévy, o usuário prefere ter 
medo do controle, ao invés de usar e praticar o poder que já tem. A segunda alternativa seria um modo de empoderar-se da própria rede.

Com vistas a esses condicionantes, o filósofo e educador francês aposta em um modelo de educação que deve garantir a nova forma de produção do conhecimento baseada na inteligência coletiva, cujas ferramentas são as tecnologias digitais. Tais tecnologias, por suposto, têm consequências e influências em todas as esferas da dimensão humana, as quais vão muito além da educação, posto que também perpassam as relaçóes de trabalho e a vida em sociedade, como sistemas de formação e sistemas de reconhecimento. Daí a aposta de Lévy (1999, p. 208) nesse novo modelo de sociedade: "Estou profundamente convencido de que permitir que os seres humanos conjuguem suas imaginaçóes e inteligências a serviço do desenvolvimento e da emancipação das pessoas é o melhor uso possível das tecnologias digitais."

Acreditando piamente no poder da "inteligência coletiva" e passados mais de vinte e cinco anos desde o surgimento do conceito, na atualidade, Lévy tem-se dedicado a desenvolvê-lo e ampliá-lo, passando a acrescentar o termo "reflexiva". Segundo ele, a inteligência coletiva impulsiona o desenvolvimento humano e, ao aprimorá-la, chegaremos, enfim, a um "ciclo virtuoso autoorganizado" (LÉVY, 2014b, p. 18). A interconexão da humanidade com a internet, o desenvolvimento da economia do conhecimento, a ascensão da computação em nuvem (cloud computing) e do big data são indicadores do aumento da nossa capacidade cognitiva e evidenciam a passagem do caminho que nos levará a um outro estágio de inteligência mais avançada, atingindo a reflexividade, avalia Lévy (2014a).

Considerando que esta tem sido a orientação estratégica que atualmente tem direcionado suas pesquisas, Lévy avalia que a inteligência coletiva reflexiva impulsiona a etapa do conhecimento auto-organizado que atingirá uma metalinguagem comum. Baseando-se em torno da conexáo com a internet e o uso intensivo da tecnologia, tal forma potencializará nossas capacidades de aprendizado pessoal e social. Assim explica Lévy (2016, p. 139):

As mídias sociais (blogs, wiki, jogos multi-player e redes de todos os tipos) estáo sendo cada vez mais usadas para aprendizado formal (escolas, universidades) e aprendizado informal (comunidades de prática, redes individuais de aprendizado, etc.). $\mathrm{O}$ uso de uma metalinguagem comum busca construir pontes entre sistemas nacionais de concessão de diplomas, entre disciplinas, entre trajetórias formais e informais. 
Avalia ainda que esta será “[...] a era tecnológica mais avançada do conhecimento reflexivo, com seu ideal de inteligência algorítmica” (LÉVY, 2014b, p. 24), e as tecnologias da informação ocupam um papel preponderante nesse circuito da consciência reflexiva, uma vez que contribuem para acelerar seu processo. Desse modo, o conhecimento reflexivo, produto da era tecnológica, ocorre na medida em que há o aumento técnico da cognição. Isso significa que teremos um conhecimento baseado em princípios mais transparentes e métodos científicos mais aperfeiçoáveis do que temos hoje, graças ao meio algorítmico.

Trata-se, portanto, de atingir a inteligência algorítmica, a qual, em suma, significa o surgimento do conhecimento reflexivo por meio da criação de uma ciência matematizada da inteligência humana, incluindo a metalinguagem (LÉVY, 2014a, 2017). Para o pensador francês, a novidade está em que o conhecimento reflexivo é um conhecimento que conhece a si mesmo e "[...] surge da multidão de açóes humanas imersas no espaço e no tempo" (LÉVY, 2014b, p. 25), numa forma de ciberdemocracia universal, que vai muito além dos limites espacial e dos guetos de uns poucos esclarecidos, detentores do conhecimento como outrora.

A considerar o aumento técnico da cognição e a "inteligência algorítmica" na esfera pública da cibercultura e da ciberdemocracia universal, as reflexóes mais recentes de Pierre Lévy apontam para uma sociedade baseada na elevada concentração de dados (the data-centric society), onde o grandioso tráfico humano de dados decorrentes do uso das redes sociais virtuais propiciará, no futuro, a criação e o "[...] exercício de uma nova cidadania de software" (LÉVY, 2016, p. 139), pois é no campo do software que haveremos de intermediar nossas relações, seja no âmbito social, seja no político ou econômico, incluindo o educativo como meio de aprendizagem. Nessa perspectiva, eis o prognóstico de Lévy (2016, p. 140) quanto à esfera pública e aos direitos de acesso de dados:

No futuro, nossas interações com dados, algoritmos e redes exigem a construção ou modelagem de uma nova camada de nossa subjetividade. No campo sensorial dilatado da civilização do futuro, simulação digital e realidade aumentada vão se misturar com fluidez e darão origem a ecossistemas de ideias geradas pela inteligência algorítmica em torno de pessoas, comunidades, lugares, objetos concretos e temas de aprendizagem. 
Assim, o papel da educação será o de oportunizar o processo contínuo de crescimento e fluxo deste "ecossistema de ideias", o qual, de modo interativo, garantirá o armazenamento e o controle de dados informacionais jamais vistos na história da humanidade. Isto não se dará somente em torno de grupos e comunidades, mas também em torno do próprio indivíduo, configurado como um "avatar semântico" e explicado pelo educador da era do virtual nos seguintes termos:

Eu designo o ecossistema de ideias que diz respeito a uma pessoa pelo termo avatar semântico. Esta aura brilhante quer exibir em um modo holográfico (por exemplo, usando o vidro do Google) os dados que os indivíduos produzem, coletam e analisam, os algoritmos que eles criaram e os que eles usam, as conexôes que eles definem. Nossos avatares semânticos querem nos dar a oportunidade de refletir sobre nossa experiência de vida, proteger nossa saúde, planejar melhor nossos empreendimentos cognitivos, gerenciar nossas relações sociais. (LÉVY, 2016, p. 140).

\section{A Ciberbultura E A CUltura DA VigilâNCIA}

A "aura brilhante" que Lévy projeta em nossos "avatares semânticos" do futuro rumo à sociedade do conhecimento é vista por vários estudiosos do assunto com certa desconfiança. Trata-se de um utopismo de tipo tecnoliberal, por depositar total confiança na ressignificação da tecnologia, avalia Rüdiger (2011, p. 159ss). Logo, o próprio conceito de inteligência coletiva de Lévy também é passível de críticas, porque se configura como uma manobra do filósofo entusiasta da tecnologia que consiste em retirar a "inteligência" do ser e da consciência social para lançá-la no plano meramente tecnológico. Ou seja, o coletivo dessa inteligência se encontra não no plano da sociedade, todavia, no plano da tecnologia (MIÈGE, 2009, p. 18; MATTELART, 2006, p. 71, BEZERRA, 2017).

Por isso, a ciberdemocracia pensada por Lévy nada mais é do que a criação fantasiada e ingênua de um ciberespaço livre de controle pelos sistemas de poder, onde a "inteligência coletiva", mediada pela tecnologia, passa a ser uma "inteligência sem sujeito" (RÜDIGER, 2011, p. 167). A igual modo, Barreto (2005, p. 121) argumenta que, ao usar o termo "inteligência coletiva", Lévy fez referência "[...] a uma consciência coletiva, solidária, formada a partir do compartilhamento de ideias, mas desconsiderou que a produção de fato ocorre num espaço social real em que sujeitos interagem.” Ou seja, não se pode prescindir, na produção do conhecimento, do sujeito produtor do 
conhecimento e seu espaço de interação entre sujeitos, posto que a rede em si é depositária do conhecimento, mas não produtora dele. ${ }^{2}$

Se os conceitos e teorias de Pierre Lévy sobre a cibercultura como espaço da ciberdemocracia e de produção de novas formas de conhecimento despertam tais suspeitas, ainda mais se evidenciam seus limites, se levarmos em conta as observaçóes oportunas para o propósito do nosso estudo, elaboradas pelo sociólogo David Lyon $(1994,2006,2015)$ sobre o que ele denomina a "cultura da vigilância", seguidas de perto por outros autores, como Bauman (BALMAN; LYON, 2013), Ramonet (2016), Harari (2016), Assange (2013, 2015), Greenwald (2014), entre outros.

Segundo Lyon, na sociedade atual, a vigilância se caracteriza pela coleta de informaçôes, com o objetivo de controlar algo ou alguém, e, no contexto da cibercultura, dá-se, sobretudo, pelo uso dos dispositivos eletrônicos. A “[...] maneira como usamos esses dispositivos afeta o quanto a vigilância atinge o sucesso" no mundo de hoje, observa Lyon (2015, p. 3). Contudo, para entender com mais amplitude o estado da questão da vigilância, na sociedade atual, haveremos de retroceder um pouco na história, a fim de compreender as metamorfoses do sentido da vigilância.

Lyon identifica três estágios, coordenados por três grandes esferas de vigilância moderna: o Estado, a Sociedade e a Cultura. A primeira fase caracteriza-se pelo "Estado de Vigilância" ou um Estado Orwelliano, também conhecida como vigilância em massa. A visão clássica, eternizada no livro de George Orwell, 1984 (2009), com agentes públicos vigiando todos os cidadãos, utilizando a tecnologia estatal, e onde todas as açóes são coordenadas por um poder centralizado, é descrita pelo conceito de panóptico, identificado por Foucault ainda nos anos setenta, em sua obra Vigiar e Punir (2013).

$\mathrm{Na}$ segunda fase, verifica-se um alargamento do poder de vigiar para o âmbito da "Sociedade de Vigilância". Nesse momento, o monopólio da vigilância estatal diminui, tendo, agora, outros agentes não-públicos que se ocupam da vigilância, embora persistam as estruturas hierárquicas centralizadas e os agentes treinados para vigiar. Um exemplo é a atuação das

\footnotetext{
${ }^{2}$ Ciente de outras críticas de que padece o pensamento de Lévy, além das já mencionadas aqui (como a visão iluminista de emancipação pela educação, o conceito de universalizaçáo do espaço do saber, a utopia planetária), as quais, infelizmente, nâo podemos tratar neste artigo, em vista do espaço e do objeto deste estudo. Assim, para o aprofundamento do assunto, no Brasil, indicamos a obra de Francisco Rüdiger (2011), especialmente o Capítulo VII, que trata da Tecnoutopia liberal humanista de Pierre Lévy, além da obra de Mattelart (2006).
} 
grandes corporaçóes compartilhando dados dos usuários. Ou seja, trata-se do compartilhamento de informaçóes pessoais para fins comerciais, com a geração de propagandas personalizadas.

$\mathrm{Na}$ atualidade, atingimos também a "Cultura de Vigilância". Nesse estágio, "[...] a vigilância não é apenas sofrida por nós, se não que também participamos dela", salienta Lyon (2015, p. 3). Portanto, aqui se modificam os agentes da vigilância, não mais identificados num único polo. Trata-se de um sentido de vigilância ao que Lyon costuma denominar "ban-óptico" (todos vigiam todos) e "sinóptico" (muitos vigiam poucos), em contraposição ao primeiro estágio, caracterizado por Foucault como "pan-ótico" (onde poucos vigiam muitos) (LYON, 2006, p. 3-20). Ou seja, o panóptico original, com sua estrutura física, está restrito a ambientes educacionais, industriais e prisionais, no entanto, o conceito sofreu ressignificação diante da nova realidade virtual, daí o sentido de "ban-óptico".

Assim, a vigilância contemporânea é mais difusa, posto que se encontra disseminada culturalmente e sem centro decisório controlador. Cada usuário da tecnologia da informaçáo pode, em tese, exercer a atividade de vigiar. As pessoas podem "espiar", "espionar", "investigar” as atividades cotidianas do outro. E isso tudo com a colaboração desse outro, já que ele mesmo compartilha publicamente suas atividades nas redes sociais, de livre e espontânea vontade. Por conseguinte, o próprio usuário é um colaborador, através do uso peculiar de dispositivos que servirão para o seu rastreamento pessoal, como smartphones, tablets, relógios inteligentes, pulseiras conectadas ou outros dispositivos vestíveis.

Dentro desse marco atual da vigilância que agora atinge os patamares da cultura, por exemplo, "[...] o Facebook facilitou novos níveis de vigilância do consumo, agora baseados nos autos relatos de gostos e preferências" (LYON, 2015, p. 29) e, assim, os usuários não se percebem controlados e têm a ilusão da liberdade de escolha, mas, em verdade, elas são feitas pelos algoritmos do Facebook. Essa rede social, portanto, oferece recompensas sociais que a todos nos agradam, no contexto da cibercultura: gratuidade, instantaneidade, facilidade, sociabilidade etc. E é aí onde mora o perigo, segundo Assange (2013, p. 46), porque o Facebook "[...] é um jeito de deixar as pessoas à vontade com o fato de estarem revelando seus dados pessoais." Ou seja, esse fenômeno não se restringe a uma questão prática do indivíduo, de utilização das ferramentas tecnológicas que aparentemente e despretensiosamente facilitam nossa vida social. Trata-se, em última instância, de um fenômeno que diz respeito à nossa 
condição humana, de controle por meio da vigilância; é o panóptico perfeito, observa Assange (2013).

Essa forma de vigilância e controle póem à prova a utopia da ciberdemocracia de Lévy, porque uma das questóes cruciais apontadas neste contexto da cibercultura diz respeito justamente ao âmbito da privacidade e ao direito à liberdade do indivíduo, os quais são fundamentais e têm custado tão caro à democracia. Os serviços de redes sociais gratuitos, por exemplo, além de esconderem por trás um elevado custo social (LÉON, 2014, p. 2), não são tão gratuitos quanto parecem. A rede livre e gratuita, a qual ironicamente costumamos chamar FreeNet, parece não ser tão livre assim, afinal, se não pagamos por um serviço, somos o próprio produto desse serviço (RAMONET, 2016).

Nesse sentido, vivemos um novo regime de mediação da informação, no qual existe constante vigilância dos passos virtuais para fins econômicos ou políticos, com a consequente personalização da experiência digital. Esta, por sua vez, requisita uma rede de profissionais altamente capacitados, que vão desde engenheiros, passando por psicólogos e profissionais do marketing etc, com o objetivo de criarem algoritmos de classificaçáo digital, definindo "[...] a escolha da informação que será disponibilizada ao usuário de uma plataforma digital." (BEZERRA, 2017, p. 79).

Em suma, projetada pelos indivíduos ante os dados que produzem, coletam e analisam, a "aura brilhante" dos nossos avatares semânticos desejada por Lévy é também uma forma de controle sobre o próprio indivíduo. Isso, por um lado; por outro, e se contrapondo ao otimismo de Lévy, Assange (2015, p. 57) alerta que o avanço da tecnologia da informação "[...] prenuncia a morte da privacidade para a maioria das pessoas e aproxima o mundo do autoritarismo."

Sobre esses aspectos da cultura da vigilância apontados por Assange, ainda voltaremos a refletir mais adiante. Mas, a esta altura e diante dessa nova faceta da vigilância que se forma e se realiza, no âmbito difuso da cultura, cabe a pergunta que nos remete ao próprio contexto deste estudo: as tecnologias digitais, em efeito, são tecnologias que possibilitam o conhecimento, na era da cibercultura, a liberdade do indivíduo e o alcance em larga escala da ciberdemocracia, como pretende Lévy? Ou melhor seria dizer que se trata de tecnologias de controle, disfarçadas em formato de diversão oferecidas pela indústria cultural? 
No que concerne a essas formas disfarçadas de tecnologias de controle em formato de diversão, Lyon (2015, p. 4) é ainda mais provocador: "Podemos imaginar Orwell revirando-se do seu caixão: nos tornamos todos Wilson Smiths e amamos o Big Brother?" Com razão, o reality show e seu grande público só têm sentido nessa "sociedade do espetáculo", protagonizada e profetizada já no final dos anos sessenta do século passado por Guy Debord, onde o espaço privado se torna público, por meio da vigilância da tela e em tempo real. Numa afirmação esclarecedora, Debord (2003, p. 17) assim descreve o espetáculo, nessa sociedade: "Sua única mensagem é: 'o que aparece é bom, o que é bom aparece'.” É nela que se apela para o efeito otimista e positivo ligado à diversão, numa espécie de novela interativa com a participação pública na esfera privada. "É a vida concreta de todos que se degradou num universo especulativo", acrescentaria Debord (2003, p. 19).

A projeção feita por Guy Debord adquire agora, no contexto da cibercultura, novos contornos, visto que, além da vida concreta que se degrada no universo especulativo, tem-se ainda o papel exercido pela cultura consumista na vigilância contemporânea, indicada por Bauman como "vigilância líquida". No contexto atual da "modernidade líquida" - termo também cunhado por Bauman (2001) como a metáfora perfeita para designar a sociedade baseada na fluidez das relaçóes humanas e sociais, onde tudo é efêmero e adquire uma velocidade vertiginosa -, o monitoramento dos usuários de redes sociais e a venda dos seus dados fazem parte da própria existência desse tipo de negócio, fluido, rápido e versátil.

No contexto da vigilância líquida, as pessoas promovem a si mesmas e têm suas informaçóes comercializadas pelas companhias. E, tal como sublinha Bauman, o "[...] consumo é um investimento em qualquer coisa - que importa para o 'valor social' do indivíduo e sua auto-estima." (BAUMAN; LYON, 2013, p. 13). Assim, o propósito do consumo não é a satisfação das necessidades e desejos, porém, o reconhecimento da náo-decisão livre e consciente dos indivíduos/consumidores, os quais buscam apenas se adequar como "mercadorias vendáveis", fugindo do medo de inadequação social. Bauman identifica, nesse fenômeno social, a "comoditização" ou a "recomoditização" do consumidor, ou seja, os membros "[...] dessa sociedade são eles mesmos consumidores e commodities." (BAUMAN; LYON, 2013, p. 32-33).

Com efeito, nesse contexto, a vigilância dos consumidores se torna um negócio e caracteriza uma espécie de servidão voluntária dos usuários, porque, 
passivamente, alimentam os bancos de dados das empresas e ainda se sentem gratos e recompensados, quando recebem sugestóes - baseadas obviamente no histórico que eles próprios construíram. O exemplo, da plataforma Google, faz todo sentido aqui:

Cada comentário em um blog representa mais informaçáo para o crawler do Google indexar, para ajudá-lo a fornecer melhores resultados nas buscas. Cada clique no Google Maps representa mais informação sobre o comportamento do consumidor e cada e-mail no Gmail é um indicativo de nossa rede humana de conexóes, e o Google pode usar tudo isso para inventar novos produtos ou só vender melhor os anúncios. (ANDERSON, 2009, p. 127).

Seria este, porventura, o "brilho" do nosso avatar semântico? A aparente mágica que nos surpreende, posto que surgida de repente na nossa tela, através dos anúncios publicitários escolhidos à nossa medida, é apenas o marketing digital moderno. "A cada dia, o Google anota nossas buscas, estimulando estratégias de marketing customizadas" (BAUMAN; LYON, 2013, p. 1), e essa manipulação da escolha se dá pela sedução, e não pela coerção, pois, enquanto nesta, de fato, existe uso da força e eliminação da escolha, no caso da primeira, o indivíduo tem papel ativo de colaboração, de autopromoção.

Podemos asseverar, então, que estamos numa sociedade confessional, na qual "[...] a exposição pública do privado é uma virtude e obrigação." (BAUMAN; LYON, 2013, p. 31). Nesse sentido, náo se trata apenas da “invasão" da privacidade, mas da própria “evasão" da privacidade, já que esta é propagada e promovida pelo próprio usuário. Numa acertada observação sobre esses novos contornos da vigilância, Lyon (BAUMAN; LYON, 2013, p. 2-3) sentencia:

A vigilância suaviza-se especialmente no reino do consumo. Velhas amarras se afrouxam à medida que fragmentos de dados pessoais obtidos para um objetivo são facilmente usados com outro fim. A vigilância se espalha de formas até entâo inimagináveis, reagindo à liquidez e reproduzindo-a. Sem um contêiner fixo, mas sacudida pelas demandas de "segurança" e aconselhada pelo marketing insistente das empresas de tecnologia, a segurança se esparrama por toda parte.

As demandas de "segurança", providencialmente anunciada por Lyon, adquirem total sentido, quando analisamos a situação da vigilância no plano público e político. Por isso, além da análise da vigilância no âmbito privado 
da cultura do consumo, devemos lembrar ainda que a vigilância e o Big Data não existem isolados. Muito pelo contrário, as grandes bases de dados "[...] são produtos dos sistemas políticos, econômicos e tecnológicos" e servem aos interesses da vigilância, ao que Lyon $(2015$, p. 55, 69) denomina Big Data Surveillance, ou vigilância pelo Big Data.

No caso dos sistemas econômicos, os dados na era do Big Data são vistos como material bruto para os negócios e elemento vital para a economia, sendo utilizados para criar novas formas de valores econômicos (MAYERSCHONBERGER; CUKIER, 2013, p. 5ss). No caso dos sistemas políticos, sabemos que, pelas revelaçốes recentes dos casos Wikileaks e Snowden, a coleta massiva de metadados foi amplamente utilizada pelo serviço de espionagem do governo norte-americano (GREENWALD, 2014). E, ainda que o discurso estatal vigente insista em afirmar que a vigilância vem se expandindo como resposta do Estado à segurança internacional e ao terrorismo global (LYON, 2006), na sociedade da cultura da vigilância, todos e cada indivíduo são alvos, pois os metadados permitem rastrear e saber quem fala, com quem e por quanto tempo. Logo, isso seria já suficiente para identificar as pessoas e prever seus comportamentos, já que os metadados são "altamente pessoais", avalia Lyon (2015, p. 83).

Contudo, se as informaçóes trazidas pelos casos Assange e Snowden se tornaram publicamente reveladoras do potencial manipulador dos dados dos cidadãos, usuários da rede pelos órgãos governamentais, mais preocupante ainda é a aparente apatia dos usuários. Por isso, ademais da privacidade, a ilusão do anonimato também é merecedora de atenção, no contexto da cibercultura. Um exemplo dessa situação aparece ilustrada no documentário FreeNet (2016), quando perguntado aos usuários se eles se incomodavam com a exposiçáo aberta de seus dados pessoais na rede. Primeiro, todos respondiam dizendo que náo tinham nada a esconder. Porém, quando indagados se se poderia deixar um microfone aberto para captar suas falas, numa mesa de um restaurante, todos foram unânimes em dizer que não permitiriam. A mesma reação de desconfiança e negatividade foi apresentada pelos usuários, quando indagados se aceitariam receber do correio postal uma carta aberta. Todos sabiam que se tratava de uma violação de direitos individuais, digna de reprovação.

Todavia, o que revelam esses modos distintos de comportar-se? Nas três situaçóes descritas, todas evidenciam a flagrante exposição de dados pessoais e sua possível manipulação para fins alheios aos do indivíduo. Entretanto, no 
caso da exposição virtual, parece que tal risco se torna menos perceptível aos olhos do usuário. Ou seja, a virtualidade tem sido, inclusive, capaz de camuflar mais e melhor esses riscos, o que a credencia a obter passivamente as bênçãos e as benesses de seus usuários, os quais, ingenuamente, preferem acreditar ser este um espaço neutro, inclusive, reafirmando e propagando aos "quatro ventos" o discurso da democracia digital.

A situação do armazenamento de dados pessoais, como o uso ingênuo da cloud computing, é emblemático nesse sentido. Lyon adverte que fortaleza é a melhor metáfora que define a ação cloud computing, porque, quando um usuário faz upload dos seus dados para a "nuvem", em realidade, está enviando cópia dos seus arquivos para os servidores de uma empresa que tem localização geográfica específica. Por isso, de um modo categórico, Lyon (2015, p. 34) é enfático: "Pense em 'Fortaleza', não em 'Nuvem'." As pessoas pensam em nuvens como algo imaterial, dando a impressão despretensiosa de que as informaçôes estão "nas nuvens", como se estivessem por aí, sem lugar preciso. Ou seja, "[...] o ciberespaço não está 'separado' do mundo real. Existe uma falsa ideia de separação entre o mundo 'online' e 'offline'. Tal visão pode produzir uma certa irresponsabilidade entre os usuários.” (LYON, 2015, p. 42).

Em verdade, o discurso da democracia digital (ou a ciberdemocracia de Lévy) esconde o seu lado mais perverso, pois, em troca da liberdade, de usar livremente a rede, por exemplo, o usuário pensa estar em segurança, quando fornece seus dados pessoais. E, no fim das contas, tal como adverte Ramonet, num instigante escrito titulado $O$ império da vigilância (2016), o usuário nunca estará seguro, e ainda por cima será usurpada sua liberdade, na medida em que fragmentos de seus dados pessoais obtidos poderão ser usados para direcionar suas escolhas. Do mesmo modo, é um ledo engano pensar que dominamos a rede; ela, sim, já nos domina, porque nos mantém atados a ela, de tal maneira que até mesmo nas atividades mais triviais do dia a dia cada vez mais dependemos dos seus serviços, por isso, revelamos nossos dados e consentimos (tacitamente ou não) o seu uso. Por isso, sustenta Ramonet (2016), a democracia digital é um discurso para enganar "tontos". Nada mais apropriado para entender o seu contexto que a afirmação de McLuhan (1994), considerado por muitos como o profeta da era digital: nesse modelo societário, o meio é a mensagem, porque é também o seu conteúdo. Ou seja, o meio digital não é somente a forma; ele é o próprio conteúdo desse modelo comunicacional. 
Disso tudo se conclui que a vigilância nunca é neutra. E, apesar de muitos de seus defensores sustentarem que ela é sempre necessária, como um caminho para monitorar situações de ameaça ou perigo para o Estado, Ignacio Ramonet (2016) argumenta que esse tem sido o grande pretexto para nos manter controlados pela rede. Por que nos vigiam? E a resposta é: para monitorar os sinais de ameaça e evitar atentados em grande escala. No entanto, os riscos e as ameaças não se dão somente na esfera das macrorrelaçốes de poder, porém, também ocorrem na esfera do micropoder, isto é, aquelas relaçóes que envolvem o cotidiano a que está submetido cada indivíduo, usuário da rede.

Por isso, a vigilância nada tem a ver com a segurança, mas com o poder. $\mathrm{O}$ caso mais recente da Cambridge Analytica e sua influência na última eleição presidencial dos EUA é emblemático nesse sentido, segundo relata a Comissária de Justiça da Uniâo Europeia:

As últimas revelações sobre a maneira como Cambridge Analytica teve acesso, através do Facebook, aos dados pessoais de mais de 50 milhóes de pessoas são inquietantes. Mas, o mais inquietante é que esta informação tenha sido utilizada para modificar o comportamento dos cidadãos $e$ influenciar em seu voto e, em resumidas palavras, no funcionamento da nossa democracia [...]. O mais alarmante é que, ainda que somente cerca de 270.000 pessoas deram seu consentimento e instalaram a controvertida aplicação, segundo a imprensa, se recolheram os dados de 50 milhóes de usuários sem seu consentimento. (JOURAVA, 2018, grifos nossos).

No caso do Brasil, suspeita-se de prática semelhante adotada por empresas de marketing (inclusive estrangeiras), nas eleiçôes presidenciais de 2018: por meio do WhatsApp, tais empresas enviaram massivamente mensagem políticas, fraudando dados pessoais dos seus usuários (MELLO, 2019). Nesse contexto, haveríamos de nos perguntar, então, se num futuro próximo gostaríamos de ter outras pessoas decidindo, com base no nosso perfil de usuário (no nosso avatar semântico), quem deverá ser o presidente do nosso país, quem tomará as decisóes políticas por nós, assinala Harari, em entrevista (GALINDO, 2018). Afinal, graças ao Big Data, pela primeira vez na história, será possível conhecer uma pessoa melhor que ela mesma, inclusive, hackear a seres humanos e decidir por eles. Tais propósitos nem mesmo lograram os serviços de inteligência mais sofisticados, em seu momento áureo, como era a função de espionagem da KGB e da CIA, no século passado, ressalta o mesmo Harari, em sua obra Homo Deus (2016). 


\section{As PRÁTICAS EDUCATIVAS NA ERA DA CIBERCULTURA}

A considerar o dito até aqui, urge pensar criticamente sobre as nossas práticas, sobretudo do ponto de vista educativo, na era da cibercultura. Por exemplo, o uso de soluçóes técnicas - como de criptografia pessoal para proteção de dados, amplamente defendido por Assange (2015) - parece não ser o único caminho, porque a maior parte dos cidadãos nem tem conhecimento técnico suficiente para se proteger dos ataques deliberados de seus dados pessoais. Se o preparo técnico, individualizado, não é suficiente, por outra parte e num contexto jurídico, as leis de proteção à privacidade por si só também "[...] não resolvem os problemas, não mais do que a tecnologia poderia, ainda que existem importantes iniciativas que estabelecem suporte", sustenta Lyon (2015, p. 134).

Enfim, mais que soluçóes técnicas ou jurídicas, é necessário educar para a prática da cidadania, na era da cibercultura. Mais que propiciar e incentivar o uso das tecnologias da informação no nosso cotidiano e no ambiente educativo, apostando no "exercício de uma nova cidadania de software", como postula Lévy (2016, p. 139), é preciso refletir sobre suas implicaçóes sociopolíticas. Afinal, “[...] o uso destas 'ferramentas' não é uma brincadeira inocente ou mesmo uma atividade neutra” (LYON, 2015, p. 138), nem pode ser considerada uma prática pedagógica desinteressada, meramente utilitária. É necessário, pois, educar para o comportamento crítico e prudente, na era da cidadania digital.

Para tanto, primeiramente há que se combater a noção imprecisa da "sociedade da informação", a qual, insiste (e nâo por acaso) em se confundir com "sociedade do conhecimento", na era da cibercultura. Nesse sentido, a previsão de Mattelart (2006, p. 71) parece oportuna para repensar nossas práticas educativas:

A imprecisão que envolve a noção de informação coroará a de "sociedade da informaçáo". A vontade precoce de legitimar politicamente a ideia da realidade hic et nunc desta última justificará os escrúpulos da vigilância epistemológica. A tendência a assimilar a informaçáo a um termo proveniente da estatística (data/dados) e a ver informaçáo somente onde há dispositivos técnicos se acentuará. Assim, instalar-se-á um conceito puramente instrumental de sociedade da informação. Com a atopia social do conceito, apagar-se-ão as implicaçóes sociopolíticas de uma expressão que supostamente designa o novo destino do mundo. 
Desde um ponto de vista filosófico e da práxis educativa, lidar com esse "novo destino", assinalado por Mattelart, implica, em primeiro lugar, combater sua visão instrumentalmente algorítmica e estatística, ou a tese equivocada de que o acúmulo de dados ou informação equivale a conhecimento. Dominar informaçôes e dados não necessariamente significa ter conhecimento, pois, à diferença do primeiro processo, o segundo requer capacidade reflexiva e de discernimento. Ou seja, o processo formativo da atividade de educar vai muito além da simples tarefa de garantir o fluxo de informação, através das tecnologias digitais.

Implica, ainda, analisar criticamente o modo como vemos e usamos as tecnologias da informação, as redes sociais e os espaços virtuais de interação, estabelecendo novas práticas relacionais com as tecnologias digitais. Dentre essas práticas e no contexto da cultura da vigilância, cujas novas tecnologias são desenvolvidas em prol desse modelo societário, há que ter em conta outros mecanismos explicativos para tal, incluindo os de controle. Mais que permanecer seduzidos e encantados com a "aura brilhante" dos nossos avatares semânticos, tal como postula Lévy, cremos ser necessário alimentar uma postura vigilante sobre o que ideologicamente se intenta reafirmar e legitimar como uma prática "escrupulosa da vigilância epistemológica", denunciando justamente seu sentido inescrupuloso. Ou seja, é preciso educar para a "contravigilância", tal como reivindica Lyon, em sua obra $O$ olho eletrônico (1994).

Lyon aponta algumas estratégias para a "contravigilância" e suas indicaçôes para superar a "paranoia pós-moderna" da sociedade da vigilância a que estamos todos submetidos parecem ser de fundamental importância para, ao menos, repensar nossa prática educativa rumo à cidadania, na era da cibercultura. Por exemplo: (a) mais que propagar ingenuamente o seu uso indiscriminado, é necessário promover o debate e a participação dos indivíduos sobre os serviços já estruturados na rede; (b) mais que manter a atitude passiva da condição de usuário, consumidor, é preciso reposicionar nossa condição de sujeitos e enfrentar o debate sobre o direito à personalidade, com nova fórmula postada e como alternativa ao dataimagem, (c) logo, é preciso manter a submissão dos sistemas de vigilância a constantes escrutínios e atenção do público. Enfim, é necessário postular um processo educativo do uso da rede o qual capacite um usuário mais crítico e menos ingênuo, consciente dos mecanismos de proteção disponíveis e defensor dos direitos e garantias fundamentais do indivíduo, como a liberdade e a privacidade. 
Fomentar essa discussão na esfera da educação é incrementar, em consequência, o debate da sociedade civil organizada em âmbitos regulatórios do ecossistema da internet, os quais devem contar com o apoio não só dos profissionais da educação, mas também com o debate inclusivo e transdisciplinar de outros profissionais, como os da tecnologia, da justiça, de grupos ativistas, dos governos etc. A iniciativa da lei de proteção de dados, como a que entrou em vigor no espaço da União Europeia (SANCHÉS, 2018), aponta para essa direção. Ainda que pareçam iniciativas tímidas frente aos grandes desafios do anonimato e da privacidade, na era da cibercultura, tais regulamentos estabelecem que, sem o consentimento expresso do usuário, utilizar seus dados não é somente imoral, é também ilegal. Ademais, coincidem com a máxima defesa dos estados democráticos de direito: “[...] proteger os dados é proteger a democracia.” (JOURAVA, 2018). Mesmo antes dessas iniciativas no âmbito jurídico, Lyon já se mostrava esperançoso quanto ao futuro e às possíveis mudanças. Para ele, é necessário garantir o espaço da privacidade e da cidadania: "[...] é a participação pública sem medo. Isso é parte da segurança humana, envolve as relaçôes humanas e está ligada vitalmente com a prosperidade humana." (LYON, 2015, p. 140).

Por conseguinte, o direito à privacidade é um direito que deve ser claramente estabelecido, amplamente defendido e juridicamente reconhecido pelos governos atuais e pelos estados democráticos. Trata-se de uma questão de dignidade humana e de liberdade civil. Ou seja, desde um ponto de vista da "invenção democrática" - para usar a mesma expressão de Claude Lefort (2011), ao se referir aos direitos que vão surgindo nos processos de sociedades abertas e que, portanto, são conquistas permanentes das sociedades democráticas -, a privacidade deveria ser hoje, no contexto da cibercultura, um componente essencial da democracia e da vida humana: um valor essencial. E não somente porque vivemos sob a égide da vigilância, em seu sentido cultural, mas porque a vigilância em sentido estatal já acontece muito antes do advento da internet. Logo, as ameaças à privacidade não são novidades do mundo tecnológico moderno. Ocorre que o conceito de privacidade, na era da cultura da vigilância, aos poucos, está se distanciando da proteção da dignidade humana e das liberdades democráticas.

Por isso, Lyon (2015, p. 128) aponta para uma ética do cuidado, inclusive do cuidado com a privacidade. Isto é, no contexto da cultura da vigilância, velar pela privacidade dos indivíduos é um dever do Estado. Até porque, no atual alcance da vigilância proporcionada pela cibercultura, 
haveremos de refletir seriamente sobre os perigos desse estado de vigilância, cujo potencial também poderia servir a interesses totalitários. A biometria, por exemplo, poderia ser amplamente utilizada como mecanismo de controle nesse contexto, observa Harari (2016).

Enfim, é necessário ter consciência de que já estamos no auge da cultura da vigilância, cujo olho eletrônico é uma realidade onipresente (LYON, 1994). E, se a informação se tornou um dos bens mais preciosos da sociedade atual, em face dos novos problemas dela decorrentes, também é preciso implementar novas teorias explicativas, capazes, inclusive, de suscitar o debate a propósito de se deve o indivíduo renunciar, em prol da sociedade da informação, às conquistas e direitos fundamentais, tais como o direito à liberdade e à privacidade. Diga-se, de passagem, direitos conquistados a duras penas, no decorrer da história.

\section{CONSIDERAÇÓEs FinaIS}

Quando Michel Foucault anunciou, ainda nos anos setenta do século passado, que a vigilância ocupa um lugar primordial na organização das sociedades modernas, onde o poder trata de exercer o maior controle possível, mediante complexas técnicas e estratégias de vigilância, seguramente nem mesmo ele tinha plena consciência do alcance que atingiriam essas "complexas técnicas e estratégias de vigilância" no futuro. Agora, no contexto atual da cibercultura, a qual nos cabe viver o presente do futuro em relação ao tempo do pensador de Vigiar e punir (FOUCAULT, 2013), sua afirmação parece mais precisa e atual que nunca e se encaixa como uma luva, caprichosamente tecida para o nosso tempo. A tese de Lyon de que já atingimos a "cultura da vigilância" (1994, 2006), onde prevalece o que Ramonet denomina "o império da vigilância” (2016), dá conta de garantir a atualidade do pensamento de Foucault.

Por isso, ainda que reconheçamos o esforço de seu compatriota, Pierre Lévy, em compreender o tempo atual da cibercultura, visualizando um espaço fértil para a produção do conhecimento baseado na inteligência coletiva e na ciberdemocracia, suspeitamos (e também nos juntamos a outros autores já citados neste estudo) se, em efeito, sua teoria náo se aproximaria muito mais de um utópico tecnoliberal do que de um realismo crítico do nosso tempo. A contar pela análise de Lyon, Bauman, Ramonet, entre outros analisados neste trabalho, a balança parece pender muito mais para o lado foucaultiano 
que para o lado lévyniano. Em efeito, a realidade que se nos impóe é muito mais dura e cruel com o advento da cibercultura, se a compararmos com a ingenuidade do mundo feliz dos nossos "avatares semânticos", anunciado por Pierre Lévy (2016).

A propósito, combater a visão alienante e ilusória do anonimato e da privacidade, quando entramos no (aparente e feliz) parque humano da virtualidade, deve ser o primeiro passo em direção à tomada de consciência da nossa condição humana, na era da cibercultura. Afinal, qual a diferença entre essa condição de aceitaçáo, sem resignação, isto é, essa inércia total do usuário, o qual vende sua liberdade e privacidade em troca da segurança na rede, de qualquer Estado totalitário de outrora? Talvez, a principal diferença resida na capacidade de alcance e na exposição da barbárie. No caso do uso da rede, a internet atinge uma população bem maior e a barbárie da prisão é silenciosa. Considerada como virtual e "livre" (FreeNet), a rede é quase que imperceptível aos olhos de quem navega por ela.

Assim, contrariando a posiçáo de um dos discípulos de Lévy no Brasil, Lemos (2015, p. 197), que cita Neuromancer como um romance que descreveria apropriadamente o estado do mundo atual, somos inclinados a pensar que a posição de Lyon se situa mais próxima da realidade, posto que outros romances seriam metáforas mais apropriadas para o estado atual da vigilância, na modernidade líquida, como é o caso dos poderes sombrios da prosa de Franz Kafka.

Em que pese esse estado kafkiano, quiçá seja o momento de encorajar a cidadania, na era da cibercultura, considerando inclusive a necessidade e a urgência de suscitar o debate em torno de uma proposta de educação baseada na ética do cuidado e da responsabilidade, no mundo da virtualidade, de sorte a promover a postura crítica e educativa da "contravigilância". No nosso humilde entendimento, o simples fato de intentar despertar do sonho, daquilo que Debord (2003, p. 20) afirma ser "o mau sono da sociedade moderna acorrentada, que ao fim e ao cabo não exprime senão o seu desejo de dormir", por si só, já indica um outro caminho possível: o do despertar para a proteção e o resguardo incondicional de direitos e conquistas fundamentais para a humanidade, como é o caso da garantia da liberdade e da privacidade do indivíduo. E, mais que nunca, a educação tem um papel crucial nesse cenário, ainda que isso possa soar como um velho clichê, já desgastado e sem sentido, no ambiente da cibercultura. 
MIRANDA, A. L. Cyberculture and education: points and counterpoints between the vision of Pierre Lévy and David Lyon. Trans/form/ação, Marília, v. 44, n. 1, p. 45-68, Jan./Mar., 2021.

\begin{abstract}
This paper tries to confront Lévy's visible optimism about cyberculture as a space for the production of collective intelligence and education for social democratization, with David Lyon's critical stance on the culture of vigilance and its socio-political effects. Philosophical and qualitative, whose research source is essentially bibliographic, it is a comparative study, in which one seeks to establish the elementary differences between Lévy and Lyon's posture on cyberculture. Consequently, and rrecognizing Lyon's theses on the illusion of anonymity and the risks of the end of privacy in the age of cyberculture, the article concludes by pointing out some indications about the new educational practices in this context.
\end{abstract}

Keywords: Cyberculture. Education. Cyberdemocracy. Surveillance.

\title{
REFERÊNCIAS
}

ANDERSON, C. Free-Grátis: o futuro dos preços. Rio de Janeiro: Elsevier, 2009.

ASSANGE, J. Quando o Google encontrou o Wikileaks. São Paulo: Boitempo, 2015.

ASSANGE, J. et al. Cypherpunks: liberdade e futuro da internet. São Paulo: Boitempo, 2013.

BARRETO, A. M. Informação e conhecimento na era digital. Transinformaçáo. [online], Campinas, v. 17, n. 2, p. 111-122, 2005.

BAUMAN, Z. Modernidade Líquida. 1. ed. Rio de Janeiro: Jorge Zahar, 2001.

BAUMAN, Z.; LYON, D. Liquid Surveillance: a conversation. Cambridge: Polity, 2013.

BEZERRA, A. C. Vigilância e cultura algorítmica no novo regime global de mediação da informação. Perspectivas em Ciência da Informaçáo, Belo Horizonte, v. 22, n. 4, p. 68-81, out./dez. 2017.

DEBORD, G. A sociedade do espetáculo. Brasil: Projeto Periferia, 2003.

FOUCAULT, M. Vigiar e punir. Nascimento da prisão. 27. ed. Petrópolis, RJ: Vozes, 2013.

FREENET [documentário]. Direção: Pedro Ekman. 94min, color. Disponível em: https://www.youtube.com/watch?v=TSomRix04fQ. Acesso em: 8 nov. 2016. 
GALINDO, C. Yuval Noah Harari, el auto "Sapiens": la tecnología permitirá "hackear" seres humanos [entrevista]. El País semanal, Madrid, 29 ago. 2018. Disponível em: https://elpais.com/elpais/2018/08/20/eps/1534781175_639404.html. Acesso em: 29 ago. 2018.

GREENWALD, G. Sem lugar para se esconder: Edward Snowden, a NSA e a espionagem do governo norte-americano. Rio de Janeiro: Sextante, 2014.

HARARI, Y. N. Homo Deus: A Brief History of Tomorrow. 1. ed. Londres: Harvill Secker, 2016.

JOURAVA, V. Proteger los datos es proteger la democracia. El País. Madrid, 29 mar. 2018. Disponível em: https://elpais.com/elpais/2018/03/27/ opinion/1522154135_052349.html Acesso em: 30 mar. 2018.

LEFORT, C. A invençáo democrática: os limites da dominação totalitária. 3 ed. Belo Horizonte: Autêntica, 2011.

LEMOS, A. Cibercultura: tecnologia e vida social na cultura contemporânea. Porto Alegre: Sulina, 2015.

LEMOS, A.; LÉVY, P. O futuro da internet: em direção a uma ciberdemocracia planetária. São Paulo: Paulus, 2010.

LÉON, E. A. S. La información y privacidad en la era digital. Tsantsa. Revista de Investigaciones Artísticas, Cuenca, n. 2, p. 1-5, dez. 2014.

LÉVY, P. A inteligência coletiva: por uma antropologia do ciberespaço. 3. ed. São Paulo: Loyola, 2000.

LÉVY, P. Cibercultura. São Paulo: Editora 34, 1999.

LÉVY, P. Ciberdemocracia. Lisboa: Instituto Piaget, 2003.

LÉVY, P. Pierre Lévy talks about Cyberdemocracy at Senac [Conferência]. São Paulo: Senac, 2014. Disponível em: https:/www.youtube.com/watch?v=OmzDuAN5_ zg\&index=7\&list=WL Acesso em: 9 dez. $2014 \mathrm{a}$.

LÉVY, P. The philosophical concept of algorithmic intelligence. Spanda Journal, Netherlands, v. 2, p. 17-26, 2014 b.

LÉVY, P. The data-centric society. Azimuth (International Journal of Philosophy), Roma, v. 7, p. 129-140, 2016.

LÉVY, P. La pyramide algorithmique [essais]. Revue Sens Public, Universidade de Montreal, Canadá, p. 1-38, dez. 2017. Disponível em: http://sens-public.org/article1275. html. Acesso em: 20 maio 2018.

LYON, D. The Electronic Eye: The Rise of Surveillance Society. Minnesota: University of Minnesota Press, 1994. 
LYON, D. The search for surveillance theories. In: LYON, D. Theorizing Surveillance: The Panopticon and Beyond. Portland: Willian, 2006. p. 3-20.

LYON, D. Surveillance after Snowden. Cambridge: Polity, 2015.

MATTELART, A. História da sociedade da informação. 2. ed. São Paulo: Loyola, 2006.

MAYER-SCHONBERGER, V.; CUKIER, K. Big Data: A revolution that will transform how we live, work and think. Boston: Houghton Mifflin Harcourt, 2013.

McLUHAM, M. Understanding media: The extensions of man. Cambridge: MIT Press, 1994.

MELLO, P. C. WhatsApp admite envio massivo ilegal de mensagens nas eleiçóes de 2018. Folha de S. Paulo. São Paulo, 8 out. 2019. Disponível em: https://www1.folha.uol.com. br/poder/2019/10/whatsapp-admite-envio-massivo-ilegal-de-mensagens-nas-eleicoesde-2018.shtml. Acesso em: 10 out. 2019.

MIÈGE, B. A sociedade tecida pela comunicação: técnicas da informação e da comunicaçáo entre inovação e enraizamento social. São Paulo: Paulus, 2009.

NAÇÓES UNIDAS. Report of the Special Rapporteur on the promotion and protection of the right to freedom of opinion and expression. Frank La Rue, 16 maio 2011. Disponível em: http://www2.ohchr.org/english/bodies/hrcouncil/docs/17session/A. HRC.17.27_en.pdf. Acesso em: 20 jun. 2018.

ORWELL, G. 1984. Sáo Paulo: Companhia das Letras, 2009.

RAMONET, I. El imperio de la vigilancia. Madrid: Clave Intelectual, 2016.

RÜDIGER, F. As teorias da cibercultura: perspectivas, questóes e autores. 1. ed. Porto Alegre: Sulina, 2011.

SANCHÉS, Á. El ecosistema de Internet vive desde este viernes la mayor regulación de su historia en la EU. El País, Cuaderno Internacional. Madrid, 24 maio 2018. Disponível em:https://elpais.com/internacional/2018/05/24/actualidad/1527159920_297244.html. Acesso em: 24 maio 2018.

Recebido: 28/12/2018

Aceito: 05/8/2020 
MIRANDA, A. L. 